Revista Brasileira de Informática na Educação - RBIE

Brazilian Journal of Computers in Education

(ISSN online: 2317-6121; print: 1414-5685)

http://br-ie.org/pub/index.php/rbie

Submission: 30/Jan/2017;

Camera ready: 23/Nov/2017; $1^{\text {st }}$ round notif.: 08/May/2017;

Edition review: 28/Mar/2018;
New version: $23 / \mathrm{Jun} / 2017$ Available online: 28/Mar/2018; $2^{\text {nd }}$ round notif.: $31 / \mathrm{Jul} / 2017$ Published: 07/May/2018

\title{
Flow Theory to Promote Learning in Educational Systems: Is it Really Relevant?
}

\author{
Wilk Oliveira dos Santos \\ Center of Excellence for Social Technologies (NEES) \\ Federal University of Alagoas (UFAL) \\ wos@ic.ufal.br \\ Diego Dermeval \\ Center of Excellence for Social Technologies (NEES) \\ Federal University of Alagoas (UFAL - Penedo) \\ diego.matos@penedo.ufal.br
}

\section{Leonardo Brandão Marques}

Education Center (CEDU)

Federal University of Alagoas (UFAL)

leobmarques@usp.br

\author{
Ig Ibert Bittencourt \\ Center of Excellence for Social Technologies (NEES) \\ Federal University of Alagoas (UFAL) \\ ig.ibert@ic.ufal.br \\ Seiji Isotani \\ Institute of Mathematics and Computer Science (ICMC) \\ University of São Paulo (USP) \\ sisotani@icmc.usp.br \\ Ismar Frango Silveira \\ Computers and Informatics Faculty \\ Mackenzie Presbyterian University \\ ismar.silveira@mackenzie.br
}

\begin{abstract}
Flow Theory has been increasingly applied to Computers and Education to address several topics within this field (e.g., motivation, engagement, learning performance and so on). At the same time, in comparison with other recent theories related to Computers and Education, (e.g., Self-Determination Theory, S-Curve Theory, Intrinsic motivation, etc.), is a young topic, with different open research questions. Additionally, the Computers and Education community still lacks a comprehensive understanding of how Flow Theory is used in the area. Thus, this paper presents a Systematic Literature Review aiming to identify how students' flow state are measured during learning activities, how such activities are designed, which are the flow models used in Computers and Education and which are the main benefits of being in the flow state for the students. The main findings of this work are: (1) there is positive evidence about the benefits of applying Flow Theory in Computers and Education, especially, for increasing students' learning, to generate students' satisfaction, and to enable exploratory behavior; (2) the majority of studies use questionnaires to manual identify students' flow state; (3) a great diversity of flow state scales have been used; (4) the majority of studies are not designing activities for leading students to the flow state, and (5) the Csikszentmihalyi' flow model is more used. Finally, we conclude this work by showing some promising and interesting research opportunities that are underexplored in current research and practice.
\end{abstract}

Keywords: Flow Theory, Flow State, Flow Experience, Computers and Education, Systematic Literature Review

Cite as: dos Santos W. O., Bittencourt, I. I., Dermeval, D., Isotani, S., Marques, L. B., \& Silveira, I. F. (2018). Flow Theory to Promote Learning in Educational Systems: Is it Really Relevant?. Brazilian Journal of Computers in Education (Revista Brasileira de Informática na Educação - RBIE), 26(2), 29-59. DOI: 10.5753/RBIE.2018.26.02.29 


\section{Introduction}

Computers and Education (C\&E) have been a growing research area, addressing different contexts related to computer-based education solutions and covering a plethora of topics, for instance, Educational Games (Connolly et al. 2012 and dos Santos et al. 2017), Intelligent Tutoring Systems (ITS) (Woolf 2015 and, Paiva et al. 2015), Adaptive Hypermedia Systems (Brusilovsky and Maybury 2002) and many others. Another topic that has been addressed by different researchers in several areas is the concept proposed by Csikszentmihalyi (1975), named Flow Theory. Indeed, there are different ways of addressing this topic in C\&E, such as measuring students' flow state when they are performing computer-based learning activities (Payne et al. 2011, Seifert et al. 2011 and Sinnamon et al. 2012], designing learning activities that aid students to achieve the flow state (Kiili et al. 2012), correlation studies between flow state and an increase in students' learning and so on (Pavlas et al. 2010 and Eisenberger et al. 2005).

Although the increasing application of Flow Theory to C\&E, for instance, in comparison with other important Theories relates to C\&E (i.e., Self-Determination Theory, S-Curve Theory, Intrinsic Motivation, and others), exist few empirical studies published in this field, and recent works have highlighted the importance to conduct empirical studies to address specific C\&E problems, for instance: the lack of automatic mechanisms to identify if a student is in the flow state (D'Mello and Graesser 2012), the impact of students' flow experience (Hamari et al. 2016 and Pavlas et al. 2010), the need for techniques to measure flow state levels (Kiili et al. 2012 and Heutte et al. 2013) and the need of adaptive mechanisms to aid students achieving the flow state based on student modeling (Hamari et al. 2015 and Santos et al. 2015). However, there is still a lack of the C\&E community about a systematic literature review presenting empirical studies related to the application of Flow Theory to C\&E, and presenting a state of the art of this domain.

Hence, the objective of this work is to conduct a systematic literature review (SLR) to find out how Flow Theory has been applied to C\&E. We investigate whether there is real evidence of the benefits of using this theory to support C\&E challenges. Furthermore, we also need to understand: (1) how the students' flow state has been identified during computer-based learning activities (2) how learning activities have been designed to lead students achieving the flow state; and (3) which flow models have been used in C\&E problems.

In this paper, we used the SLR method Kitchenham and Charters (2007) to identify, evaluate, interpret and synthesize the available studies to answer particular research questions on the application of Flow Theory to C\&E, and to establish the state of evidence with in-depth analysis. In this way, this paper presents the results of an SLR on studies published from January 2005 to July 2015, and was conducted following a predefined review protocol. Our decision on such period was made because we intend to gather more recent papers about the topic, considering emerging technologies that could be used for the joint use of Flow Theory and C\&E.

This paper is organized as follows. Section 2 presents a background about flow theory as well as a review of current topics in C\&E. Section 3 describes the SLR method used in this review. In Section 4, we present the results of the quality assessment of this review. Section 5 first presents an overview of the studies and then reports the findings of the review along with an analysis and discussion of each research question. Section 6 discusses the threats to the validity of our work. Finally, Section 7 points out some conclusions, presents further research to be explored on the use of Flow Theory in C\&E and describes future works. 


\section{Background}

The goal of this section is to present the key concepts related to Flow Theory and C\&E.

\subsection{Flow Theory}

The notion of "flow state" was introduced by Csikszentmihalyi (1975) as a technical term to describe a good feeling or "optimal experience" that people have as a motivating factor in their daily activities, such as at work, sports, and artistic performance (Faiola et al. 2013). According to this author, the key to understanding flow state is the "autotelic experience" concept (from the ancient Greek $\alpha \cup \tau o \tau \varepsilon \lambda \eta \zeta \varsigma$, or "self-goal"). Autotelic experience is the result of an activity or situation that produces its own intrinsic motivation, rewards, or incentives, specifically without any outside goals or rewards.

Since the establishment of the basis of Csikszentmihalyi's Flow Theory, several approaches have been presented in order to describe this kind of experience. Csikszentmihalyi (1990) describes nine necessary dimensions in order for an activity to prompt a flow state: (1) clear goals; (2) immediate feedback; (3) a match between personal skills and challenges; (4) merge of action and awareness; (5) facilitate concentration on the task, (6); aid a sense of control; (7) loss of selfconsciousness during the task; (8) sense of time changed; and (9) the experience of becoming "autotelic". Hoffman and Novak (1996) summarized the dimensions proposed by Csikszentmihalyi into five dimensions: (1) enjoyment; (2) telepresence; (3) focused attention; (4) engagement; and (5) time distortion. On the other hand, Rodriguez-Sanchez and Schaufeli (2008) stated that the previous dimensions could be simplified into just three key aspects: (1) absorption, (2) enjoyment, and (3) intrinsic interest.

Based on the recent literature, the minimum requirements in order for an activity to lead an individual to flow state, it should provide a balance between challenge's level and ability required for the person to complete the activity. If the difficulty of a challenge is greater than the person's skill level, he/she gets anxious. By contrast, if the difficulty of the challenge is lesser than the person's ability, it tends to be a boring activity (Admiraal et al. 2011).

\subsubsection{Flow Models}

Over the time, different conceptual models have been proposed in order to describe flow state. These models established parameters to position the flow state among other emotional states and to measure flow state level, through flow state scales and others instruments. Csikszentmihalyi (1975) was the first researcher to propose a model to describe flow state. He proposed the flow as an emotional state opposite to apathy, located between arousal/anxiety/worry control/relaxation/boredom, (see Figure 1). 


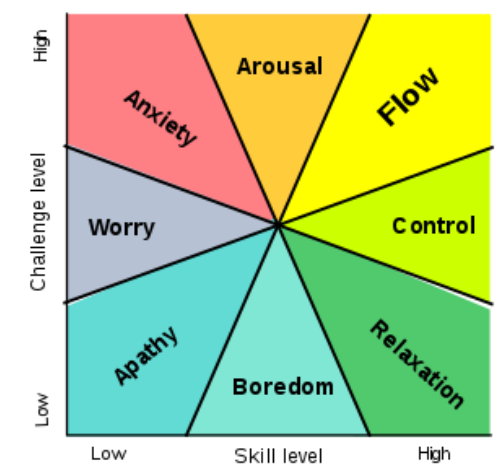

Figure 1: Csikszentmihalyi original flow model.

In the first model, Csikszentmihalyi describes seven different emotional states related to flow: (i) Arousal is the physiological and psychological state of being awoken or of sense organs stimulated to a point of perception. It involves activation of the reticular activating system in the brainstem, the autonomic nervous system, and the endocrine system, leading to increased heart rate and blood pressure and a condition of sensory alertness, mobility, and readiness to respond.

Following, (ii) Control refers to practicing newly acquired skills beyond the point of initial mastery. The term is also often used to refer to the pedagogical theory that this form of practice leads to automaticity or other beneficial consequences. (iii)Anxiety is an emotion characterized by an unpleasant state of inner turmoil, often accompanied by nervous behavior, such as pacing back and forth, somatic complaints, and rumination. The next emotional refers (iv) Relaxation in psychology, is the emotional state of a living being, of low tension, in which there is an absence of arousal that could come from sources such as anger, anxiety, or fear. $(v)$ Worry refers to the thoughts, images, and emotions of a negative nature in a repetitive, uncontrollable manner that results from a proactive cognitive risk analysis made to avoid or solve anticipated potential threats and their potential consequences.

Almost opposite to flow, ( $v i$ ) Boredom is an emotional or psychological state experienced when an individual is left without anything in particular to do, is not interested in his or her surroundings, or feels that a day or period is dull or tedious. Finally, totally opposite to flow, (vii) Apathy is a lack of feeling, emotion, interest, and concern. Apathy is a state of indifference, or the suppression of emotions such as concern, excitement, motivation, and/or passion. In the original Csikszentmihalyi model, flow is an emotional state that people can feel during specific activities, especially, activities that provide a balance between people skill level and activity challenge level and immediate feedback, representing state fully immersed in a feeling of energized focus, full involvement, and enjoyment in the process of the activity. In essence, flow is characterized by complete absorption in what one does and loses the sense of space and time (Csikszentmihalyi 1975). Some years later, new researches have been conducted and new models have been proposed. Csikszentmihalyi proposed a new model (see Figure 2a) based on the first one, which represents a simplification model, synthesizing the skill-challenge balance to flow state. In his new model, Csikszentmihalyi with considers that the flow state could have different levels, according to different factors. For instance, with some people, the flow experience can be more deep or strong than others.

Afterward, others researchers proposed different flow models and representations (all based on the Csikszentmihalyi's flow models). Schell (2014) proposed a slightly different model (see Figure $2 b$ ) on which flow state can vary in each people and the flow state level can be bigger or smaller at different times of the activity. In this model, Schell has also proposed the people can go in and out 
of the flow state quickly. More recently, Sala (2013) addressed flow state by dividing it into different modules (worlds), on which each state is located in a different slice of time (see Figure 2c). One important point is, this model just represents the simplification of the other models, to activities related to the general games, Dividing the levels of flow, and representing it as "worlds". Furthermore, Massimini and Carli (1988) proposed a flow model that separates the flow components in different channels, relates to different feelings and emotions (see Figure 2d). In this model, the authors highlight each different flow state level, have different Psychological components.

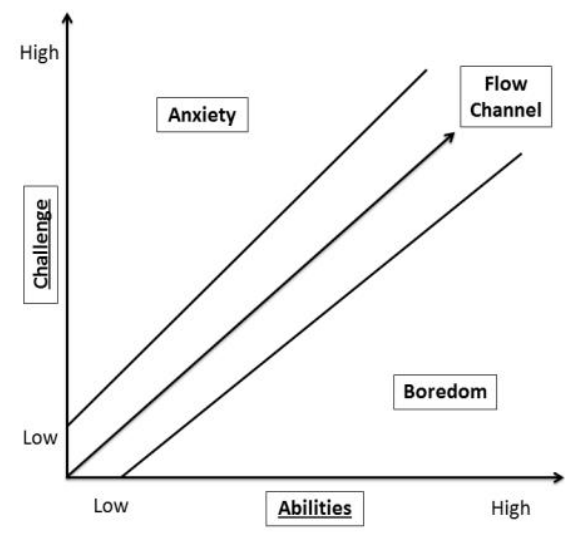

Csikszentmihalyi' flow model (a)



Sala's flow model (c)



Schell' flow model (b)



Massimini and Carli's flow model (d)

Figure 2: Flow models.

\subsubsection{Flow State Scale}

A measurement of flow state has also been addressed in the last decades. Indeed, a series of methods have been proposed in order to identify and measure flow state levels. One of the most used instrument to flow state identification is the Flow State Scale (FSS) proposed by Jackson and Marsh (1996), which is a technique to measure flow state of people in different activities, for instance: sport, physical educational activities, and others. An FSS is generally composed of questions related to different flow dimensions, such as clear goals, immediate feedback, a match between personal skills and challenges, and others. The FSS proposed by Jackson and Marsh (1996) is composed of 
36 items, representing the nine flow dimensions proposed by Csikszentmihalyi (1990), before present on Figure 1.

In the last decade, many different FSSs were proposed in order to measure flow experience considering different aspects and situations. Yoshida (2013) proposed an FSS in order to measure flow state level in the occupational tasks. This FSS is composed of 14 items and based on the nine flow dimensions proposed by Csikszentmihalyi (1990). Another proposal was made by Novak et al. (2000), which measured the flow state level in online environments. Martin and Jackson (2008) also proposed other FSS to evaluate the subjective experience of flow through two brief measures of flow.

Finally, others FSS have also been developed in order to measure flow state in Educational Games. Fu et al. (2009) and Kiili et al. (2012) proposed scales for it. The former proposed the EGameFlow, composed of 42 items and with eight flow dimensions (Concentration, Clear Goal, Feedback, Challenge, Autonomy (control), Immersion, Social Interaction, Knowledge Improvement). The later proposed the scale by taking into account nine items and ten dimensions (challenge, goal, feedback, playability, concentration, time distortion, rewarding experience, loss of selfconsciousness, and sense of control).

\subsection{Computers and Education: A Review of Current Topics}

The application of Digital Information and Communication Technologies (DICT) in education has been receiving an increasing interest and is gradually becoming leitmotiv for the teaching-learning process (Terry 2008 and Santos et al. 2015). In the last years, educational approaches have been used to promote and support the use of computer-supported educational technologies in physical and virtual learning contexts, as shown by Admiraal et al. (2011), Santos et al. (2014), Challco et al. (2014), dos Santos et al. (2017), and others, making it clear the importance of to conduct studies association these new technologies and flow theory studies. In this context, Bittencourt et al. (2016) presented a series of contemporary key themes related to C\&E, a subfield of the DICT on education, for instance: Virtual Learning Environment (VLE), Web-based Learning, Web-based Education, Collaborative Learning, Adaptive Hypermedia, Intelligent Tutoring System (ITS), Adaptive Educational Systems, Learning Management Systems, Distance Education and Educational Games.

Jonassen and Land (2012) highlighted educational system, specially VLEs are an important mechanism, capable of supporting students in different scenarios. Boisvert (2000) also points out about the importance of web-based learning, highlighting that this kind of system can improve the students' learning and provide individual educational learning spaces, especially to the field of distance education. Another relevant theme is semantic web-based education. Bittencourt et al. (2009) highlighted the semantic web-based education importance in order to design educational systems capable of meeting the contemporary educational demands (e.g., interoperability between educational systems, querying and reasoning and so on). Complementarily, Steenbergen-Hu and Cooper (2014) highlighted ITSs' results in the education as an example of the success of the application of $\mathrm{C} \& \mathrm{E}$ to provide individualized learning.

Moreover, another prolific research topic on C\&E is collaborative learning on the web. According to Roberts (2009), these educational systems are capable of integrating students in different social contexts, time period, and educational experience has a unique impact on individual learning through collaborative means. Collaborative learning techniques are pervasive on distance education, students who are not physically present at a school (Bozkurt et al. 2015). The collaborative learning 
also has grown through the growth of mobile devices in educational systems (Roberts 2009).

The use of these DICTs in educational contexts have been used along with Flow Theory concepts at several ways. For instance, researchers of VLEs, ITSs, CSCL and of other educational systems are increasingly interested in developing systems capable of driving students to flow (Katuk 2014 and Kim 2009). They have been also investigating how to design and develop frameworks to lead students to flow (Kiili et al. 2012). Particular, in the educational games and gamified systems scientific community, a big challenge is related to the identification of the students' flow experience during the use of games (Kiili et al. 2008, Kiili et al. 2012 and Pavlas et al. 2010). Thus, it is possible to identify a close relation between the Flow Theory concepts and the DICTs in education.

\section{Systematic Review}

A SLR is a means of identifying, evaluating and interpreting available research findings related to some research questions, topic areas, or phenomenon. The main purpose to conduct an SLR is to gather evidence from which some conclusions can be made Kitchenham and Charters (2008). According to them, an SLR is composed of three phases: ( $i$ ) Planning Phase - specify research questions, develop review protocol and validate review protocol; (ii) Conducting Phase - identify relevant research, select primary studies, assess study quality, extract required data and synthesize data and (iii) Documenting Phase - write review report and validate the report.

\subsection{Review Protocol}

In order to perform the planning phase, the guidelines proposed by Kitchenham (2004) were followed and the phases are presented in this section.

\subsubsection{Research Questions}

In order to achieve the objectives of this review, four main research questions (RQ) and an additional secondary question were defined and presented in Table 1, along with their description and motivation.

\begin{tabular}{l} 
Research Question \\
\hline RQ1: How students' flow state has been iden- \\
tified during computer-based learning activi- \\
ties?
\end{tabular}

RQ1.1: Which Flow State Scales (FSSs) have been used to identify students' flow state levels during computer-based learning activities?

RQ2: How computer-based learning activities have been designed to lead students to achieve the flow state?

RQ3: Which are the empirical results of applying flow state to the students' performance in computer-based learning activities?

\section{Description and Motivation}

These questions provide a starting point for understanding how students' flow state are identified during computer-based learning activities, as well as FSSs associated to these studies. The answers to these questions are important to understanding how different techniques have been used to identify flow states in the studies.

This question intends to describe how computer-based learning activities are implemented. The answer to this question identifies the techniques being used to create learning activities aiming to lead students to flow state and provide directions for future studies.

This question allows identifying empirical studies regarding flow state application in students during computer-based learning activities. The answer to this question identifies the flow state implications for students' performance and provide a general explanation of the benefits of achieving the flow state to students, as well as provide prospects for future studies in this field.

This question aims to provide an overview of the flow models used for researchers in C\&E and identify if there is a flow model pattern in this 
research field. The answer to this question allows providing a theoretical background for future studies in Flow Theory applied to C\&E.

Table 1: Research questions.

\subsubsection{Search String}

The search string was created using keywords derived from the research questions. It was created by interconnecting terms and with the following logical expression: ((flow theory OR flow state) AND $(<$ computers in education terms $>)$ ). The terms related to "computers in education" were chosen based on Bittencourt et al. (2016) and opinion of experts in this theme. The search string was applied the first time over title and abstract on the source search used in this SLR. Table 2 presents the used terms (both main terms and synonymous terms), Table 3 illustrates the simplification of the string and Table 4 describes the used search string.

\begin{tabular}{|c|c|c|}
\hline \multicolumn{3}{|c|}{ Search String Distribution } \\
\hline Id & Main Term & Synonymous Terms \\
\hline 1 & flow theory & - flow state \\
\hline 2 & educational software platform & $\begin{array}{ll}\text { - } & \text { computers in education } \\
\text { - } & \text { informatics in education } \\
\text { - } & \text { technology in education } \\
\text { - } & \text { educative software } \\
\text { - } & \text { educational software }\end{array}$ \\
\hline 3 & educational system & $\begin{array}{l}\text { - learning management system } \\
\text { - } \text { online education } \\
\text { - } \quad \text { educational environment } \\
\end{array}$ \\
\hline 4 & learning environment & $\begin{array}{ll}\text { - } & \text { virtual learning environment } \\
\text { - } & \text { artificial intelligence in education } \\
\text { - } & \text { artificial intelligence for education }\end{array}$ \\
\hline 5 & web-based learning & $\begin{array}{l}\text { - } \text { e-learning } \\
\text { - } \text { electronic learning } \\
\text { - } \text { m-learning } \\
\text { - } \text { mobile learning } \\
\text { - } \text { t-learning } \\
\text { - } \text { transformative learning } \\
\text { - internet-based learning } \\
\text { - } \quad \text { web-based education } \\
\end{array}$ \\
\hline 6 & semantic web-based education & $\begin{array}{l}\text { - } \quad \text { semantic web and education } \\
\text { - } \quad \text { semantic web for education }\end{array}$ \\
\hline 7 & collaborative learning & $\begin{array}{ll}\text { - } & \text { cooperative learning } \\
\text { - } & \text { collaborative networked learning } \\
\text { - } & \text { collaborative learning in virtual worlds } \\
\end{array}$ \\
\hline 8 & adaptive hypermedia & $\begin{array}{l}\text { - } \text { adaptive educational systems } \\
\text { - hypermedia-based education }\end{array}$ \\
\hline 9 & intelligent tutoring system & $\begin{array}{ll}\text { - } & \text { intelligent educational systems } \\
\text { - } & \text { intelligent tutor } \\
\end{array}$ \\
\hline 10 & distance education & $\begin{array}{l}\text { - } \text { distance learning } \\
\text { - } \text { *MOOC } \\
\text { - } \text { massive open online courses } \\
\text { - } \text { web-based online courses } \\
\text { - } \text { web-based courses } \\
\text { - } \quad \text { internet conducted courses }\end{array}$ \\
\hline
\end{tabular}




\begin{tabular}{l|l|l}
\hline 11 & educative game & $\bullet$ game-based learn \\
& & $\bullet$ game-based learning \\
& $\bullet$ educational game \\
& $\bullet$ game-based education \\
& $\bullet$ serious game \\
& $\bullet$ gamification \\
\hline
\end{tabular}

Table 2: Search string terms and synonyms.

\section{((1) AND ( 2 or 3 or 4 or 5 or 6 or 7 or 8 or 9 or 10 or 11))}

Table 3: Simplification of string.

(("flow theory" OR "flow state") AND ("educational software platform" OR "computers in education" OR "informatics in education" OR "technology in education" OR "educative software" OR "educational software" OR "educational system" OR "learning management system" OR "online education" OR "educational environment" OR "learning environment" OR "virtual learning environment" OR "artificial intelligence in education" OR "artificial intelligence for education" OR "web-based learning" OR "e-learning" OR "electronic learning" OR "m-learning" OR "mobile learning" OR "tlearning" OR "transformative learning" OR "internet-based learning" OR "web-based education" OR "semantic webbased education" OR "semantic web and education" OR "semantic web for education" OR "semantic web-based education" OR "collaborative learning" OR "cooperative learning" OR "collaborative networked learning" OR "collaborative learning in virtual worlds" OR "adaptive hypermedia" OR "adaptive educational systems" OR "hypermedia-based education" OR "intelligent tutoring system" OR "intelligent educational systems" OR "intelligent tutor" OR "distance education" OR "distance learning" OR "*MOOC" OR "massive open online courses" OR "web-based online courses" OR "web-based courses" OR "internet conducted courses" OR "educative game" OR "game-based learn" OR "game-based learning" OR "educational game" OR "game-based education" OR "serious game" OR "gamification"))

Table 4: Complete search string.

\subsubsection{Sources Search (Digital Libraries)}

The sources were chosen according to Dieste et al. (2009). In this way, the authors established the following source selection criteria: availability of primary studies; coverage of publications; and relevant conferences of research areas. The selected digital libraries were ACM Digital Library ${ }^{1}$, PsycNet $^{2}$, Engineering Village ${ }^{3}$, IEEE Explorer ${ }^{4}$, PubMed Central ${ }^{5}$, Science Direct ${ }^{6}$, Scopus ${ }^{7}$, Springer Link ${ }^{8}$ and Web of Science ${ }^{9}$.

\subsubsection{Inclusion and Exclusion Criteria}

The definition of inclusion and exclusion criteria aims to identify those primary studies which provide direct evidence about the research questions as well as reduce the likelihood of bias (Kitchenham and Charters 2007). Only English written studies were selected (adopted in the main scientific conferences and journals). To increase the chances of retrieving more results about the topic in this SLR. The SpringerLink digital library, for example, publishes many proceedings papers as book chapters; most of them are peer-reviewed. As such, in this review, book chapters are not considered as gray literature and was included in the SLR. Table 5 shows the inclusion and exclusion criteria

\footnotetext{
${ }^{1}$ http://dl.acm.org/

${ }^{2} \mathrm{http}: / /$ psycnet.apa.org/

${ }^{3} \mathrm{http}: / /$ www.engineeringvillage.com/

${ }^{4} \mathrm{http}: / /$ ieeexplore.ieee.org

${ }^{5}$ http://www.ncbi.nlm.nih.gov/pmc/

${ }^{6} \mathrm{http}: / /$ www.sciencedirect.com/

${ }^{7} \mathrm{http}: / /$ www.scopus.com

${ }^{8} \mathrm{http}: / /$ link.springer.com/

${ }^{9} \mathrm{http}: / /$ apps.webofknowledge.com
} 
for this work. Recall that our decision on such period was made because to gather more recent papers about the joint use of flow theory and computers and education.

\begin{tabular}{l|l}
\hline \multicolumn{1}{c|}{ Inclusion } & \multicolumn{1}{c}{ Exclusion } \\
\hline Primary studies about Flow Theory applied to Computers in Education & Non-English papers \\
\hline Studies published between 2005 and 2015 & Studies with less than or equal to 5 pages \\
\hline Peer-reviewed studies that provide answers to the research questions & Duplicated studies \\
\hline Primary sources & Secondary or tertiary studies \\
\hline & Redundant paper of the same author \\
\hline & $\begin{array}{l}\text { Works not related to Flow Theory in Comput- } \\
\text { ers in Education }\end{array}$ \\
\hline
\end{tabular}

Table 5: Inclusion end exclusion criteria.

\subsubsection{Data Extraction}

The data extraction phase was based on Kitchenham and Charters (2007). The elements for data extraction are presented as follows:

- Paper Information (Study Reference; Paper Title; Authors list; Authors Country; Affiliations; Source; Source Type (Journal, Book chapter or Conference); Year; and abstract);

- Date publication (Date between 2005 and 2015);

- Educational Technology Type (Educational Games, ITS; Virtual Learning Environment; Gamification; etc.);

- Flow Model (Csikszentmihalyi; Schell Sala; Massimini and Carli, etc.);

- Flow State Scale (Yoshida; Jackson \& Marsh; Fu, etc.);

- Software Tool (Name of software implemented or used in the study);

- Instrument for the Flow State Identification (Questionnaire; Data-log analysis; Recording user face, etc.);

- Approach for the Design of Computer-based Activities (Game design elements; Mobile elements; gamification elements, etc.);

- Flow State Consequences (Increase Learning; Increase Motivation; Internet Addiction, etc.);

- Empirical results about flow state identification (Yes or Not).

\subsubsection{Quality Assessment}

The Quality assessment phase allows classifying studies according to specific criteria (Kitchenham and Charters 2007). Quality assessment have been organized into two categories: $i$ ) general criteria (in order to evaluate the technical quality of the work, for instance, if the paper present clear goals, general discussions, explicitly threats to validation, and others (questions 1 to 8)); and ii) specific criteria - in order to evaluate the quality of studies selects regarding empirical results about Flow Theory applied to C\&E (questions 9 to 12)). Table 6 presents the quality assessment questions used as well as the possible answers and scores associated with each question.

\begin{tabular}{c|l|c|c|c}
\hline$\#$ & \multicolumn{1}{|c|}{ Quality Assessment } & \multicolumn{3}{|c}{ Possible Answers } \\
\hline QA1 & $\begin{array}{l}\text { Is there a rationale for why the study was undertaken? Mahdavi-Hezavehi } \\
(2013)\end{array}$ & $\mathrm{Y}=1$ & $\mathrm{~N}=0$ & - \\
\hline QA2 & $\begin{array}{l}\text { Is the paper based on research (or is it merely a "lessons learned" report based } \\
\text { on expert opinion)? Dyb and Dingsyr (2008) }\end{array}$ & $\mathrm{Y}=1$ & $\mathrm{~N}=0$ & - \\
\hline
\end{tabular}




\begin{tabular}{|c|c|c|c|c|}
\hline QA3 & Is there a clear statement of the goals of the research? Dyb and Dingsyr (2008) & $Y=1$ & $\mathrm{~N}=0$ & $\mathrm{P}=0.5$ \\
\hline QA4 & Is the proposed technique clearly described? Achimugu et al. (2014) & $Y=1$ & $\mathrm{~N}=0$ & $\mathrm{P}=0.5$ \\
\hline QA5 & $\begin{array}{l}\text { Is there an adequate description of the context (industry, laboratory setting, } \\
\text { products used and so on) in which the research was carried out? (Dyb and } \\
\text { Dingsyr (2008) and Mahdavi-Hezavehi (2013)) }\end{array}$ & $\mathrm{Y}=1$ & $\mathrm{~N}=0$ & $\mathrm{P}=0.5$ \\
\hline QA6 & Is the study supported by a tool? (Dermeval et al. 2014) & $\mathrm{Y}=1$ & $\mathrm{~N}=0$ & - \\
\hline QA7 & Is there a discussion about the results of the study? (Dermeval et al. 2014) & $\mathrm{Y}=1$ & $\mathrm{~N}=0$ & $\mathrm{P}=0.5$ \\
\hline QA8 & Are the limitations of this study explicitly discussed? (Ding et al. 2014) & $\mathrm{Y}=1$ & $\mathrm{~N}=0$ & $\mathrm{P}=0.5$ \\
\hline QA9 & $\begin{array}{l}\text { Does the paper present how to identify students' flow state during Computer- } \\
\text { based learning activities? }\end{array}$ & $Y=1$ & $\mathrm{~N}=0$ & - \\
\hline QA10 & $\begin{array}{l}\text { Does the paper describe how learning activities have been designed aiming to } \\
\text { aid students achieving the flow state? }\end{array}$ & $Y=1$ & $\mathrm{~N}=0$ & - \\
\hline$Q A 11$ & $\begin{array}{l}\text { Are there empirical results related to the application of flow state in students' } \\
\text { performance during computer-based activities? }\end{array}$ & $Y=1$ & $\mathrm{~N}=0$ & - \\
\hline$Q A 12$ & $\begin{array}{l}\text { Are the empirical results related to the identification of students' flow state } \\
\text { during computer-based learning activities? }\end{array}$ & $Y=1$ & $\mathrm{~N}=0$ & - \\
\hline
\end{tabular}

Table 6: Quality Assessment Form.

\subsection{Data Collection and Analysis}

In Data Collection phase, a software tool was used to support the SLR protocol. The tool called StArt (State of the Art through Systematic Reviews) (Hernandes et al. 2012) was developed to support researchers conducting SLRs. StArt was empirically evaluated, with positive results in the execution of SLRs (Heutte et al. 2013) and has several features, such as allowing the organization of papers, removal of duplicated studies, reading titles and abstracts, selecting papers to be evaluated in the next step of protocol and so on. The first step is the execution of the Search String in the search sources in order to identify and organize studies gathered from the digital libraries. The total of studies was 1,746 papers. The second step was the stage of automatic removal of duplicated articles, using the StArt tool. This stage found and removed 172 studies. Then, 1,574 titles and abstracts from the remaining studies were read, and those that not addressed the inclusion criteria were excluded (third step). As a result, 117 studies matched the inclusion criteria and were selected for the next step.

In the last step, a full-paper reading was conducted, resulting in the inclusion of 57 studies that, somehow, addressed the inclusion criteria of this SLR. Over the data collection and analysis process, six professionals $(\mathrm{PhD}$. with expertise in the field of $\mathrm{C} \& \mathrm{E}$ and gamification) participated in the process. In the titles and abstracts reading, the papers were read by two researchers and were also analyzed for other two researchers (in this case, conflicts were solved by other two researchers, through discussions based on the inclusion and exclusion criteria). In the next step - full-paper reading papers were also read by other two researchers and the papers with conflicts were analyzed by two different researchers. Finally, all the researchers participated in the organization of the data, discussion of results and writing process of this paper. The data collection and analysis process was conducted during six months (between August 2015 and February 2016). Figure 3 presents the complete process starting from studies identification and organization step (step one) until the final step (step four), on which the 57 studies were included (Appendix A present all papers included in the last step of this study). 


\section{Quality Assessment Result}

The results of the Quality Assessment were divided and classified based on the general and specific evaluation. The general evaluation refers to a group of common questions broadly used in systematic literature reviews to measure papers quality in terms of general aspects (i.e. methodology, discussion, and so on). The specific evaluation refers to a group of questions particularly created to measure the quality of papers of this SLR with respect to our research question, i.e., if the paper presents data support answering our research questions. Appendix B presents the results of quality assessment evaluation (individual paper result according to the independent and dependent questions).

According to the results, with respect to the general quality assessment criteria (questions 1 to 8 ), the evaluation of the 57 studies presented an average of about 6 points (in a maximum of 8 ) and only nine papers presented less than $50 \%$ of the general quality assessment. Moreover, the general quality assessment criteria less covered in the studies was QA6, in which only seven studies were supported by a tool. This result might have happened because few studies have used methods to automatic identification of student's flow state, as will be further explained in Section 5.2.

Regarding the specific quality assessment criteria, (questions 9 to 12), the evaluation of the 57 studies presented an average of about 2 points (in a maximum of 4). Among these studies, only seven have presented activities which were designed to aid students reaching flow state as well as have presented how the flow state was identified in the activities. Furthermore, 25 papers (44\% of the total) present empirical results related to the application of flow state in students' performance during computer-based learning activities and 47 studies (82\%) present empirical results related to the identification of students' flow state during computer-based learning activities.

Figure 4 summarizes the quality assessment results in spider graph. The overall quality of the selected studies is acceptable both from general and specific quality criteria. Taken together, these 12 criteria provided a measure of the extent to which we could be confident that a particular study's findings could make a valuable contribution to this review. Based on the quality assessment, is possible to perceive that any selected paper received a complete evaluation (12 points). The selected paper SLR027, for instance, is the paper with lower quality from the quality assessment. On the other hand, the papers SLR015, SLR017, SLR019 and SLR024, present highest quality, responding our research questions and at the same time, clear description, limitations, deep discussion of results, and others quality assessment criteria. 


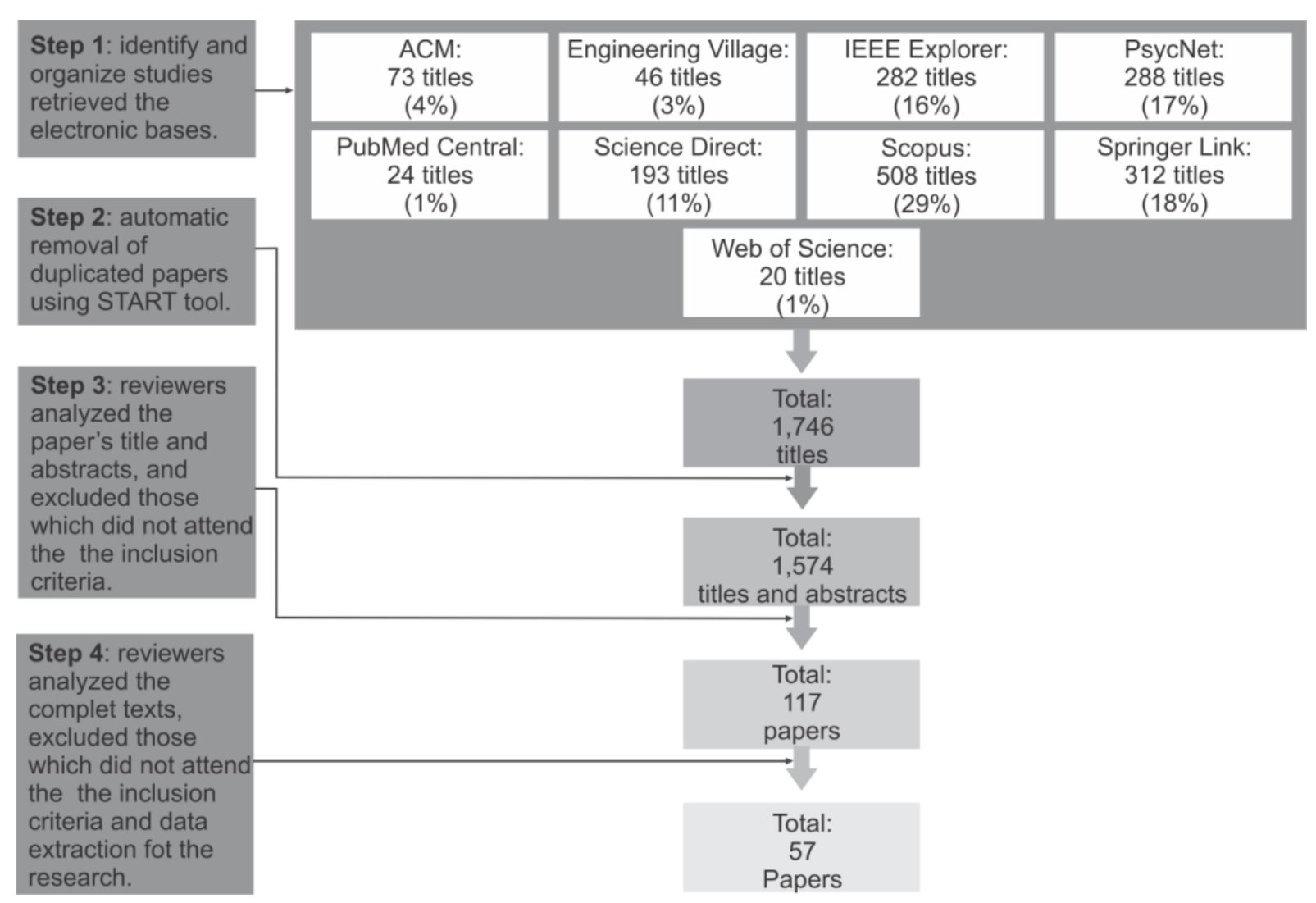

Figure 3: Studies selection process.

\section{Results}

A total of 57 studies met the inclusion criteria and their data were extracted. Prior to presenting the results and analysis for each research question of this SLR, we give a detailed overview of the general characteristics of the studies.

\subsection{Overview of the Studies}

In following, we depict general characteristics of the studies included in the review: year of publication, type of source and source type of publication, country and application domain (Appendix $\mathrm{C}$ and $D$ present the general information for studies).

\subsubsection{Publication Year}

The data extraction of general information about the studies shows that the number of studies increased through time. Although some exceptions in specific years, i.e., 2005 (with only four studies), 2006 (no studies published) and 2015 (fewer papers than the previous year), our results indicate that there is a clear trend in the application of Flow Theory to C\&E (see Figure 5).

There is a linear growth until 2014, reaching the peak of 12 articles. Note that, as the search process of this review was performed in July 2015, a slight decrease in the number of publications would be expected in 2015 because some papers might be in the press. Thus, this is probably the reason for the number of studies in 2015 be lesser than 2014. 


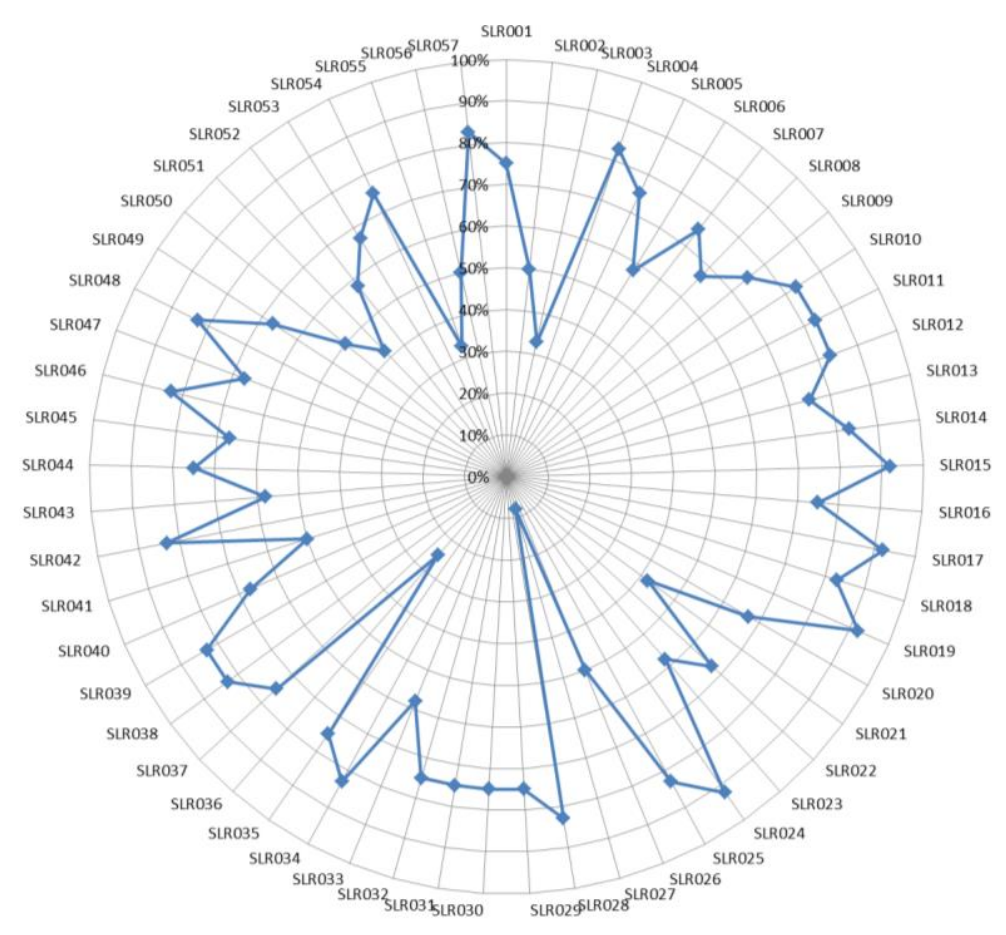

Figure 4: Quality Assessment (Grand Total Result).



Figure 5: Temporal view of the studies.

\subsubsection{Source and Source Type of Publication}

Other general data extracted from the studies were the source and source type of publication (see Appendix C). The data extracted shows that the 57 studies are distributed in 35 different sources (3 different book chapters, 6 different conferences, and 26 different journals). This result can indicate that the application of the Flow Theory to $\mathrm{C} \& \mathrm{E}$ is a multidisciplinary theme, covering and contributing with different educational topics. The most relevant source type of publication was Journal (47 papers) from different areas, for instance, C\&E, Psychology, and Education. This result endorses that the application of Flow Theory to $\mathrm{C} \& \mathrm{E}$ is a multidisciplinary topic. It may also represent that the studies in this field have a good maturity level since most of them are published in Journals. 


\subsubsection{Country}

Authors from 17 different countries and five different continents (Asia, Europe, North America, Oceania and South America) published the papers selected in this SLR. The United States of America is the country with most publications (17 papers), followed by Taiwan (13 papers) and South Korea (9 papers). Figure 6 illustrates the author's affiliations through a "words cloud". These results may indicate that this SLR topic is broadly addressed by researchers and institutions from different countries. On the other hand, they also indicate a supremacy of three countries in this research area, highlighting the importance of conducting new studies involving researchers and professionals from different countries and different social backgrounds.

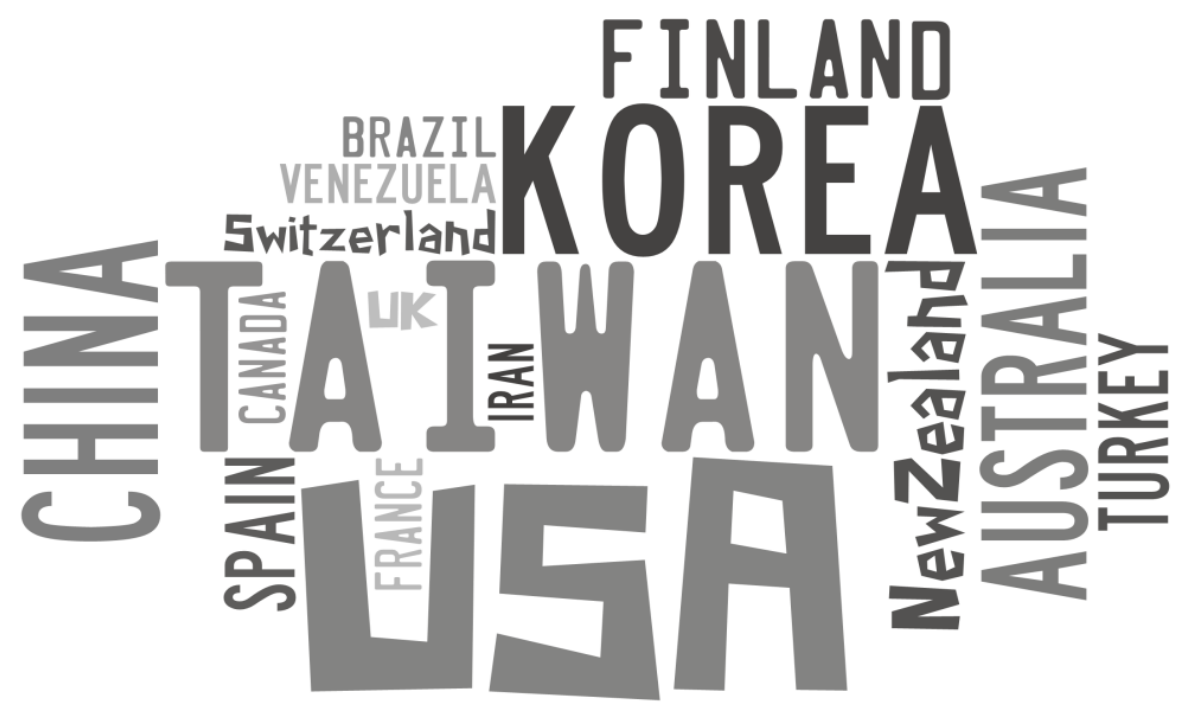

Figure 6: Countries of the included studies.

\subsubsection{Educational Technology Types}

The studies were also classified according to it type educational technology (educational technology provide by the study). We identified 15 categories for these types after extracting data from the studies (see Table 7). The e-learning category is the most addressed (12 studies), followed by educational game (11 studies), virtual learning environments (9 studies) and virtual world (6 studies). The Augmented Reality and Internet Usage categories are addressed by three studies, each one, whereas the Gamification, Intelligent Tutoring System and Mobile Learning categories have 2 studies each. Moreover, six educational technology types are addressed by only 1 study: Computer Assisted Instruction, Cyber University, Game-based Learning, Multimedia Instructional Materials, User Interface and Web-based Instruction. We could not identify the educational technology type of 1 study, thus, we categorized it as Non-Specific.

Our results suggest that Flow Theory is actually more used along with games and/or gamebased educational technologies. Considering the three categories related to games (i.e., Educational Game, Game-based Learning and Gamification), 14 studies (almost 25\% of the total) are addressing this theory to design computer-based learning activities. This result was somewhat expected since the design of game-based systems directly considers the psychological states related to the Flow 
Theory. However, as presented in Table 7, one might note the Flow Theory has been used along with several educational technologies, with an emphasis on general E-learning systems, virtual learning environments, and virtual worlds.

\begin{tabular}{|c|c|c|c|}
\hline Application Domain & Papers & Frequency & $\%$ \\
\hline Augmented Reality & SLR013; SLR015; SLR037 & 3 & $5.26 \%$ \\
\hline Computer Assisted Instruction & SLR014 & 1 & $1.75 \%$ \\
\hline Cyber University & SLR041 & 1 & $1.75 \%$ \\
\hline Educational Game & $\begin{array}{l}\text { SLR003; SLR005; SLR009; SLR017; SLR030; SLR031; } \\
\text { SLR034; SLR035; SLR050; SLR051; SLR056 }\end{array}$ & 11 & $19.30 \%$ \\
\hline E-learning & $\begin{array}{l}\text { SLR016; SLR023; SLR024; SLR028; SLR033; SLR038; } \\
\text { SLR042; SLR043; SLR047; SLR048; SLR054; SLR057 }\end{array}$ & 12 & $21.05 \%$ \\
\hline Game-based Learning & SLR029 & 1 & $1.75 \%$ \\
\hline Gamification & SLR001; SLR027 & 2 & $3.51 \%$ \\
\hline Intelligent Tutoring System & SLR004; SLR052 & 2 & $3.51 \%$ \\
\hline Internet Usage & SLR010; SLR039; SLR040 & 3 & $5.26 \%$ \\
\hline Mobile Learning & SLR019; SLR026 & 2 & $3.51 \%$ \\
\hline $\begin{array}{l}\text { Multimedia Instructional Materi- } \\
\text { als }\end{array}$ & SLR011 & 1 & $1.75 \%$ \\
\hline User interface & SLR036 & 1 & $1.75 \%$ \\
\hline Virtual Learning Environments & $\begin{array}{l}\text { SLR021; SLR006; SLR018; SLR007; SLR012; SLR025; } \\
\text { SLR044; SLR049; SLR055 }\end{array}$ & 9 & $15.79 \%$ \\
\hline Virtual World & SLR020; SLR032; SLR045; SLR046; SLR002; SLR008 & 6 & $10.53 \%$ \\
\hline Web-based Instruction & SLR053 & 1 & $1.75 \%$ \\
\hline Non-Specific & SLR022 & 1 & $1.75 \%$ \\
\hline
\end{tabular}

\subsection{RQ1: How Students' Flow State has been Identified During Computer-based Learning Activities?}

The purpose of this research question was to identify how students' flow state has been identified by the studies when they are performing computer-based learning activities. We categorized the studies according to two dimensions: instruments used (i.e., user data logs, interview and questionnaire and so on) and instrument automation level (i.e., manual, semi-automatic and automatic).

Among the 57 studies, 49 studies (86\%) proposed some mechanism for identifying the flow state. The other 8 studies (14\%) do not present any specific instrument, hence, they are categorized as Non-Specific. As shown in Table 8, the majority of the papers used questionnaires (45 studies; 79\%) to identify students' flow state, followed by User Data Logs (4 studies; 7\%) and Interview and Recording User Face (both with 2 studies; 4\%). Note that a study could have used more than one instrument, thus, the sum of percentages may be greater than $100 \%$.

\begin{tabular}{|c|c|c|c|}
\hline $\begin{array}{c}\text { Flow state identification } \\
\text { instrument }\end{array}$ & Papers & Frequency & $\%$ \\
\hline User Data Logs & SLR002; SLR034; SLR052; SLR054 & 4 & $7 \%$ \\
\hline Interview & SLR032, SLR034 & 2 & $4 \%$ \\
\hline Recording User Face & SLR018, SLR037 & 2 & $4 \%$ \\
\hline Questionnaire & $\begin{array}{l}\text { SLR001; SLR004; SLR005; SLR006; SLR007; SLR008; SLR009; } \\
\text { SLR010; SLR011; SLR012; SLR013; SLR014; SLR015; SLR016; } \\
\text { SLR017; SLR019; SLR020; SLR023; SLR024; SLR025; SLR026; } \\
\text { SLR028; SLR029; SLR030; SLR031; SLR032; SLR033; SLR034; }\end{array}$ & 45 & $79 \%$ \\
\hline
\end{tabular}




\begin{tabular}{l|l|c|c}
\hline & SLR035; SLR036; SLR037; SLR038; SLR039; SLR040; SLR041; & & \\
& $\begin{array}{l}\text { SLR042; SLR043; SLR044; SLR045; SLR046; SLR047; SLR048; } \\
\text { SLR049; SLR053; SLR057 }\end{array}$ & \\
\hline \multirow{2}{*}{ Non-Specific } & $\begin{array}{l}\text { SLR003; SLR021; SLR022; SLR027; SLR050; SLR051; SLR055; } \\
\text { SLR056 }\end{array}$ & 8 & $14 \%$ \\
\hline
\end{tabular}

Table 8: Instruments for Identifying Flow State.

The classification on the level of automation of the instruments is related to the instrument used itself. Thus, studies that used only User Data Logs or Recording User Faces are classified as Automatic, studies that used at least one manual instrument (i.e., Interview or Questionnaire) are classified as Semi-Automatic and studies that only use manual instruments are classified as Manual. The predominant automation level of the instruments is the manual identification (75\% of the studies), followed by automatic identification ( $7 \%$ of the studies) and semi-automatic (4\% of the papers). Moreover, we could not identify the type of mechanism for eight studies (14\%), thus, we categorized them in the Not Applicable category.

Figure 7 depicts the number of studies considering the instruments used to identify the flow state over the automation level of it. As shown in the figure, 43 studies relied on questionnaires to manually identify flow state and only 2 studies also used some automatic mechanism (i.e., SLR032 and SLR034) along with them. User data logs are exclusively used to automatic identify flow state by 3 studies and one study (i.e., SLR034) used this instrument along with questionnaires and interviews.

Data were generated from the users' activities, during their interaction in some educational system and, then. These data were typically analyzed through algorithms and statistical process. Otherwise, interviews are used as a non-automatic process to identify students' flow state in one study (i.e., SLR032), in this study is also used questionnaires. One study used recording user faces to automatically flow state identification and other paper (i.e., SLR037) used it along with questionnaires. This technique consists of recording the face of user and analysis their facial expression through computational algorithms.

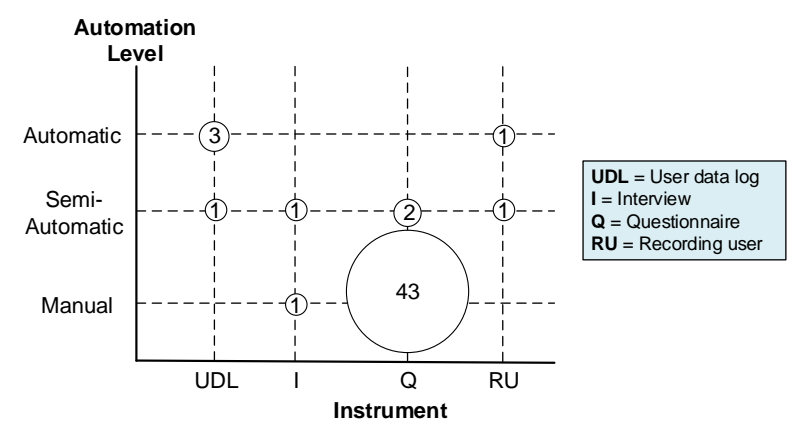

Figure 7: Instruments to identify flow state over their automation level.

\subsubsection{RQ 1.1. Which FSSs have been Used to Identify Students' Flow State Level in Comput- er-based Learning Activities?}

The purpose of this research question is to identify which flow state scales have been used in the C\&E literature. The classification of the scales (15 categories) was made after the data extraction of the studies, i.e., during the extraction, plain text data about the FSSs used in the study was captured. 
Next, in the syntheses step of this review, 15 categories were defined according to the distribution of the studies. Table 9 presents the distribution of the studies considering the identified FSSs. The predominant FSS that we identified was proposed by Jackson \& Marsh (1996) (6 studies; 11\%), followed by Novak et al. (2000), Martin and Jackson (2008) and Fu et al. (2009), each one with 2 studies $(4 \%)$. Moreover, 11 others FSSs were used in only one work each. Finally, 34 studies did not present any FSS (Non-Specific).

\begin{tabular}{|c|c|c|c|}
\hline Flow State Scale & Papers & Frequency & $\%$ \\
\hline $\begin{array}{l}\text { Adapted from Chang, Wu, Weng, and Sung } \\
\text { (2012) }\end{array}$ & SLR037 & 1 & $2 \%$ \\
\hline Adapted from Kiili et al. (2006) & \begin{tabular}{|l|} 
SLR029 \\
\end{tabular} & 1 & $2 \%$ \\
\hline Adapted from Kiili et al. (2012) & SLR009 & 1 & $2 \%$ \\
\hline $\begin{array}{l}\text { Develop an own FSS based Kiili and Lainema } \\
\text { (2008) }\end{array}$ & SLR030 & 1 & $2 \%$ \\
\hline Flow Scale for Games (FSG) & \begin{tabular}{|l|} 
SLR005 \\
\end{tabular} & 1 & $2 \%$ \\
\hline Fu et al. (2009) & SLR017; SLR022 & 2 & $4 \%$ \\
\hline Jackson \& Marsh (1996) & $\begin{array}{l}\text { SLR013; SLR026; SLR044; SLR048; SLR049; } \\
\text { SLR020 }\end{array}$ & 6 & $11 \%$ \\
\hline Jackson and Ecklund (2002) & \begin{tabular}{|l|} 
SLR002 \\
\end{tabular} & 1 & $2 \%$ \\
\hline $\operatorname{Kim}(2009)$ & SLR041 & 1 & $2 \%$ \\
\hline Martin and Jackson (2008) & SLR007; SLR016 & 2 & $4 \%$ \\
\hline Novak et al. (2000) & SLR012; SLR024 & 2 & $4 \%$ \\
\hline Shin (2006) & SLR008 & 1 & $2 \%$ \\
\hline Vollmeyer and Engeser (2003) & SLR057 & 1 & $2 \%$ \\
\hline Wang et al. (2007) & SLR011 & 1 & $2 \%$ \\
\hline $\begin{array}{l}\text { Wigand, and Nilan (1999) and Novak, Hoffman } \\
\text { and Yung (2000) }\end{array}$ & SLR053 & 1 & $2 \%$ \\
\hline Non-Specific & $\begin{array}{l}\text { SLR001; SLR003; SLR004; SLR006; SLR010; } \\
\text { SLR014; SLR015; SLR018; SLR019; SLR021; } \\
\text { SLR023; SLR025; SLR027; SLR028; SLR031; } \\
\text { SLR032; SLR033; SLR034; SLR035; SLR036; } \\
\text { SLR038; SLR039; SLR040; SLR042; SLR043; } \\
\text { SLR045; SLR046; SLR047; SLR050; SLR051; } \\
\text { SLR052; SLR054; SLR055; SLR056 }\end{array}$ & 34 & $55 \%$ \\
\hline
\end{tabular}

Table 9: Flow State Scales Used in the Studies.

In fact, we could only identify that 24 papers (42\% of the studies) used some kind of FSS. Figure 8 depicts these studies considering the FSSs over the instruments used to identify flow state. As can be seen, most of the FSSs (except for Jackson and Ecklund 2002) are used along with questionnaires (21 studies). The flow state scale proposed by Jackson and Ecklund (2002) was used by only one study along with user data log instrument to identify flow state. The flow state adapted from Chang et al. (2012) (F14) is used along with two instruments, i.e., questionnaire and recording user face. Note that the flow state proposed by Fu et al. (2009) "F5" was also used in a study along with a non-specific instrument for identifying flow state. Moreover, no studies used flow state scales along with an interview. 


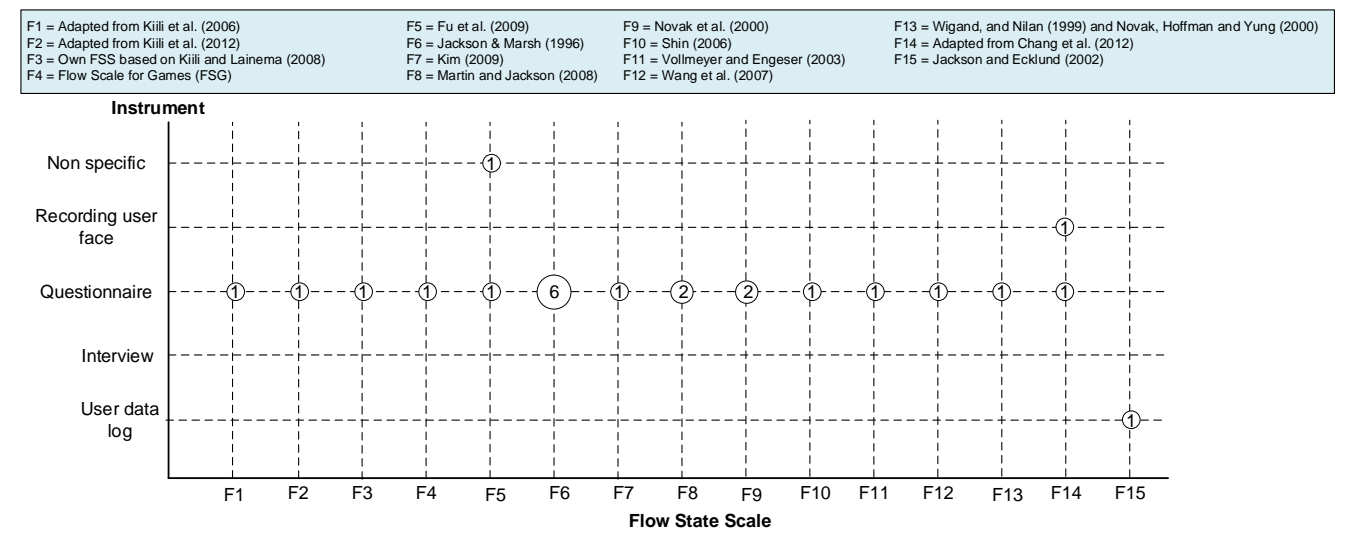

Figure 8: Flow state scales over instruments to identify flow state.

\subsection{RQ 2: How Computer-based Learning Activities have been Designed to Lead Students for Achieving the Flow State?}

The purpose of this research question is to identify the techniques used to design learning activities with the explicit focus on leading students to flow state. We identified seven categories (i.e., Computer Assisted Learning System, Game Design, GameFlow, Gamification Elements, Mobile Guide Design Principle, Skill-Challenge Balancing and Unavailable) to classify the studies in order to answer this research question.

Among 57 papers, only 13 actually presented some technique to design learning activities. Most of the papers (44 studies; $76 \%$ ) do not implement activities aiming to lead students to the flow state, as shown in Figure 9. More than half of the studies that presented such activity used Game Design Elements ( 7 studies; $12 \%$ of the total). Two studies (4\%) used a Skill-Challenge Balancing technique to design learning activities and only 1 study $(2 \%)$ used each one of the following techniques: Computer Assisted Learning System, GameFlow (which is a methodology aiming to lead students to flow state), Gamification Elements and Mobile Guide Design Principle.

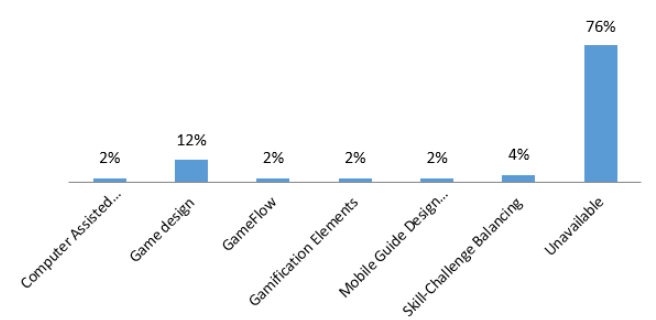

Figure 9: Approaches for Designing of Computer-based Learning Activities.

As seen in Figure 9, 76\% of studies do not design any computer-based activity in order to lead students to the flow state. This result might indicate that, although the intention of leading students to flow state, the majority of studies are not presenting any specific way to achieve this objective. In fact, only $11 \%$ of the studies are proposing some learning activity aiming to lead students to the flow state. We suspect that it might have happened because designing learning activities to aid students achieving the flow state is a complex task on which several aspects should be considered, for instance, learning objectives, instructional design, clear goals, feedback, and so on. Moreover, this 
result may also indicate that few studies have "know-how" to design such activities for addressing C\&E problems.

\subsection{RQ 3: Which are the Empirical Results of Applying Flow State to the Students' Perfor- mance in Computer-based Learning Activities?}

The purpose of this research question was to gather and classify available evidence to state how the application of flow state benefits students when they are performing computer-based learning activities. Studies were classified as "positive" if they presented positive empirical evidence about the benefits of applying flow state to students, as "negative" if they present negative empirical evidence about these benefits or as "both" if they present positive and negative empirical evidence.

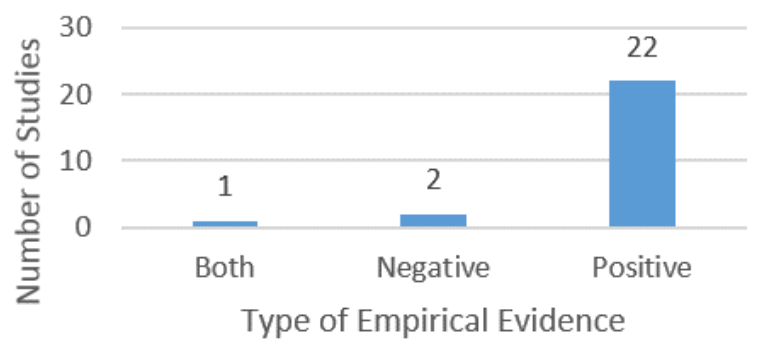

Figure 10: Types of empirical evidence.

Twenty-five studies (44\%) presented evidence about the application of flow state in computerbased learning activities, as presented in Figure 10. In fact, the two studies (SLR018 and SLR045) that reported negative evidence were not expecting these results. They both explain that the negative results were surprising since previous similar studies reported in the literature presented different results. In the study SLR018, students have demonstrated confusion and disequilibrium while were performing computer-based learning activities designed to lead them to the flow state.

Moreover, the study SLR045 pointed out that students in flow state presented a decrease in their learning. These results are utmost importance in order to encourage conduction of new studies to understand if the flow state can be harmful to students at some time, place or social context. Furthermore, one study identified negative and positive evidence for the application of flow state to students in computer-based learning activities. This study (SLR010) has conducted an examination of the dual effects of flow experience on high school students' Internet addiction and exploratory behavior, as well as on the effects of parental interventions on the dual causal processes.

As positive consequences reported on the study, they mention the exploratory behavior among the students. On the other hand, as negative consequences, the study identified that flow state in the domain of internet usage can cause addiction in the internet usage. The other 22 studies that presented some student's flow state evidence found only positive consequences. Table 10 describes the flow state benefits associated with each study. As shown in the table, it was observed an increase in student's learning when they are in the flow state, six studies reported students that achieved flow state during computer-based activities had a learning increase.

Moreover, others positive evidence were found in different studies, such as increase of satisfaction with educational activity, more in-depth reflective process, and exploratory behaviors. These positive results demonstrate that flow state is a field with positive results to C\&E, generating positive results to different contexts in the last decade, and making room to new studies in different C\&E 
domains, especially, in order to provide to students, environments capable of increasing student's satisfaction, exploratory behaviors, learning, and so on.

\begin{tabular}{|c|c|c|}
\hline $\begin{array}{l}\text { Kind of Con- } \\
\text { sequence }\end{array}$ & Consequences & Studies \\
\hline Both & $\begin{array}{l}\text { Positive: Exploratory behavior; Negative: Internet addic- } \\
\text { tion }\end{array}$ & SLR010 \\
\hline \multirow{2}{*}{ Negative } & Confusion and disequilibrium & SLR018 \\
\hline & Decreased learning & SLR045 \\
\hline \multirow{16}{*}{$\begin{array}{l}\stackrel{0}{0} \\
0 \\
0\end{array}$} & Exploratory behavior & SLR010, SLR021, SLR039, SLR40 \\
\hline & Feeling of Achievement & SLR007 \\
\hline & Creativity and Imagination & SLR002 \\
\hline & Telepresence & SLR021 \\
\hline & Facility to accept changes and adaptations & SLR036 \\
\hline & Feeling happy and cheerful & SLR012 \\
\hline & Flash of intensity & SLR015 \\
\hline & Sense of discovery & SLR015 \\
\hline & Desire for higher performance & SLR015 \\
\hline & Influential for developing dispositions to empathy & SLR017 \\
\hline & Interest in learning about games & SLR017 \\
\hline & Learner's internal locus of control & SLR041 \\
\hline & Institutional support & SLR041 \\
\hline & Learner persistence & SLR041 \\
\hline & Increase learning & $\begin{array}{l}\text { SLR012. SLR004, SLR024, SLR025, } \\
\text { SLR032, SLR033, SLR038 }\end{array}$ \\
\hline & Satisfaction & $\begin{array}{l}\text { SLR012, SLR038, SLR048, SLR057, } \\
\text { SLR016 }\end{array}$ \\
\hline
\end{tabular}

Table 10: Flow State Consequences.

\subsection{RQ 4: Which Flow Models have been Used in the Studies?}

In order to understand the maturity of the papers regarding Flow Theory's theoretical background, this question aims to identify which flow models have been used in the studies. In 39 studies (68\%), we could not identify which flow model was used. We could only identify the flow model used as theoretical background in 18 studies (32\%). Among these 18 studies, 17 used the flow model proposed by Csikszentmihalyi (1975) and only one study used the flow model proposed by Csikszentmihalyi (1975) combined to the flow model proposed by Massimini and Carli (1988). Table 11 describes these studies along with the flow model used.

These results might indicate that papers are not presenting good maturity in applying flow models to design computer-based learning activities since less than half of studies used a Flow Theory's theoretical background. Moreover, among the studies that relied on some flow model, most of them only applied the flow model proposed by Csikszentmihalyi (1975) without providing any discussion or comparison between different flow models. On the one hand, this analysis could help to identify which flow models are likely to be more suitable in order to address C\&E problems, on the hand is possible the papers are using studies more known about flow model, without conduct more deep analysis over other possibilities. 


\begin{tabular}{|c|c|c|c|}
\hline Flow State Model & Papers & Total & $\%$ \\
\hline Csikszentmihalyi (1975) & $\begin{array}{l}\text { SLR001; SLR002; SLR003; SLR005; SLR006; SLR007; } \\
\text { SLR008; SLR010; SLR014; SLR017; SLR019; SLR030; } \\
\text { SLR039; SLR043; SLR046; SLR053; SLR054 }\end{array}$ & 17 & $30 \%$ \\
\hline $\begin{array}{l}\text { Csikszentmihalyi (1975) and Massimini } \\
\text { and Carli (1988) }\end{array}$ & SLR025 & 1 & $2 \%$ \\
\hline Non-specific & $\begin{array}{l}\text { SLR004; SLR009; SLR011; SLR012; SLR013; SLR015; } \\
\text { SLR016; SLR018; SLR020; SLR021; SLR022; SLR023; } \\
\text { SLR024; SLR026; SLR027; SLR028; SLR029; SLR031; } \\
\text { SLR032; SLR033; SLR034; SLR035; SLR036; SLR037; } \\
\text { SLR038; SLR040; SLR041; SLR042; SLR044; SLR045; } \\
\text { SLR047; SLR048; SLR049; SLR050; SLR051; SLR052; } \\
\text { SLR055; SLR056; SLR057 }\end{array}$ & 39 & $68 \%$ \\
\hline
\end{tabular}

Table 11: Flow models.

\subsection{Discussion}

The results of this SLR present papers published in venues from different research areas such as C\&E, Education, and Psychology, indicating the multidisciplinary inherent to it. The results of the first research question suggest that the majority of the papers (77\% of the total) are using manual instruments (with high frequency of questionnaires) to identify students' flow state. Note that using questionnaires may increase the number of threats to the validity of the studies since students need to finish the activity for answering questionnaire's items (Wu and Chen 2015).

In some cases, there is a decrease in accuracy of the flow state identification due to the existing delay from experiencing some activity to the flow state measurement (e.g. questionnaires). Indeed, few studies used automatic instruments (i.e. analysis of students' data logs and recording user face) to measure students' flow state. This result might indicate that there is a lack of the use of more advanced computational techniques, such as educational data mining, artificial intelligence and computer vision to automatic flow state detection. In this way, these results might state a further challenge for automatic identifying students' flow state during computer-based learning activities.

In the secondary research question, we identified which FSSs were actually used along with instruments to measure students' flow state. As previously explained, less than half of studies (42\%) used some FSS to aid the flow state identification. Furthermore, fifteen different flow state scales are used, highlighting the use of the FSS by Jackson and Marsh (1996). Note that the studies that used questionnaires as instruments for measuring flow state are generally using an FSS to identify if the student reaches the flow state or which is the students' flow state level.

In fact, we might note that although many studies are using some kind of instrument to measure students' flow state, a great amount of them are not relying on FSSs to design their instruments. In addition, as several different FSSs have been used by the studies, it seems that researchers do not agree about a standard FSS to measure students' flow states during computer-based learning activities. Thus, we highlight the importance of conducting further studies to deeper evaluate the existing FSSs as well as to propose specific flow state scales suitable to be used in the context of C\&E.

The results of our second research question point out that a great majority of the papers (76\%) are actually not designing any learning activity to drive students to the flow state. As previously mentioned, we believe that an explanation of this result is that designing such activities is a quite complex task or that studies do not have the necessary "know-how" to design them regarding C\&E problems. Regarding the studies that designed learning activities, they are mostly based on games. 
Hence, these results indicate that the Flow Theory is still applied to this field with a focus on educational games and game-based activities.

According to Shernoff and Csikszentmihalyi (2009), the application of Flow Theory to education is not an exclusive domain of educational games and activities related to games elements. These authors highlight the importance of conducting researches in different $C \& E$ domains using different techniques and strategies to design computer-based learning activities in order to lead students to the flow. This result states a challenge that researchers might further address with respect to the implementation of systematic methods to design computer-based learning activities aiming to lead students to flow state.

In our third research question, we looked at the empirical benefits of applying Flow Theory to target C\&E problems. Indeed, our results show that less than half of the studies $(43 \%)$ conducted empirical evaluations of their proposals. However, among the empirical papers, most of them report positive evidence on applying this theory to this field. Our findings are consistent with several benefits such as learning increase, more in-depth reflective process, students' satisfaction, exploratory behavior, sense of cognitive presence and so on. These results are of utmost importance to the $C \& E$ research since it gathers empirical evidence about the benefits of applying Flow Theory to students, as expected by theoretical researchers (e.g. Seifert et al. 2011 and Shernoff and Csikszentmihalyi (2009)). These benefits could be potentially considered in the design of different educational systems (besides educational games), for instance, intelligent tutoring systems, MOOCs, computersupported collaborative learning systems and so on.

On the other hand, three studies reported negative evidence on the topic. Although the SLR010 paper reports positive evidence regarding exploratory behavior characteristics for the students, it also reports that internet addiction has been detected in the students. Moreover, the study SLR018 states that some students have become somewhat confused and presented some off-balance during the flow experience. The study SLR045 reports that in their experience, students had a decrease in learning because of the flow experience.

In summary, our findings suggest that there is much more positive than negative evidence regarding the application of Flow Theory to $\mathrm{C} \& \mathrm{E}$, especially related to students' learning and exploratory behavior. However, future studies (e.g., controlled experiments, conduction of meta-analysis, etc) are encouraged to verify the strength of evidence reported by such studies as well as new studies to verify flow state consequences in different perspectives.

In our last research question, we identified the flow models used by the studies as theoretical background to design computer-based learning activities. Despite aiming to aid students to achieve the flow state, our findings suggest that few studies (32\% of the total) are actually considering the theory about flow models, with a high presence of Csikszentmihalyi's model to design their activities. This result highlights that many studies are not grounding their research on theoretical background about Flow Theory. Hence, this result might indicate that most of the studies are designing from scratch their computer-based learning activities to lead students to the flow state. In this way, we encourage researchers to further consider flow models presented by the literature to address $\mathrm{C} \& \mathrm{E}$ topics. We also suggest further studies identify evidence about which flow models are more suitable, regarding for instance context, time and target public to be applied in C\&E problems.

Finally, our findings suggest that the topic addressed in this SLE is a growing field. There are relevant studies and important contributions on the use of Flow Theory in C\&E in the last decade as well as there is a potential growth in the next years, for addressing different concerns such as stu- 
dents' engagement, motivation, and learning. Additionally, a conceptual map (Appendix E) gives an overview of our results, depicting the number of studies related to each research question. Note that the term " $N=X$ " indicates the number of studies in each part of the conceptual map.

\section{Threats to Validity}

This section describes some recommendations that must be taken into account, in order to improve future replications of the SLR quality and increase the results generalization scope. In order to organize this section, the threats to validity were classified using the Internal, External, Construct and Conclusion categories (Wohlin et al. 2000).

On regarding the internal validity some subjective decisions may have occurred during paper selection and data extraction. Since that some primary studies did not provide a clear description or proper objectives and results, making difficult the objective application of the inclusion/exclusion criteria or the impartial data extraction. In order to minimize selection and extraction misleading, the selection process was performed through discussions peer-to-peer, in order to solve conflicts related to inclusion or exclusion of some papers. In this way, we tried to mitigate the threats due to personal bias on study understanding.

The external validation is concerned with establishing the generalizability of the SLR results, which is related to the degree to which the primary studies are representative for the overall reviewed topic. In order to mitigate external threats, the string search process was defined after several trial searches and validated with the consensus of all authors. We tested the coverage and representativeness of retrieved studies in the automatic database search. For some works, we could not have access to the paper, thus, it is possible that some papers related to the topic were not considered in this review. However, in order to minimize this threat, we sent an e-mail to these papers' authors requesting it.

Regarding the construct validity, the main constructs in this review were two concepts "Flow Theory" and "Computers in Education". For the first concept, we use the term "flow theory" and its synonym "flow state" to make sure that all selected studies are related to Flow Theory approaches. For the second concept, several terms related to $\mathrm{C} \& \mathrm{E}$ were used. These terms have been chosen according to the terms considered in the search string of recent SLR studies in C\&E (i.e. Bittencourt et al. 2016) as well as based on researchers' suggestions (Ph.D.'s with experience in this area). A complementary manual search was not performed in the SLR due to the fact there are no conferences and journals specifically focused on the joint use of these concepts. This threat is mitigated by including terms related to our two main constructs for the search in the seven databases.

Finally, regarding conclusion validity, it is possible that some studies excluded in this review should have been included. To mitigate this threat, the selection process and the inclusion and exclusion criteria were carefully designed and discussed by authors in order to minimize the risk of exclusion of relevant studies. Moreover, there was also a delay time between the process of collecting data and the paper writing. As our study was conducted in July 2015, probably some recent studies were also not considered in this review. However, we believe that the main results of this review would not be much impacted by this threat since we have a good amount of studies considered in this review. 


\section{Concluding Remarks}

In this work, we conducted an SLR to investigate how the Flow Theory has been applied to computers and education research. Our goal was to improve the understanding of how such theory addresses C\&E topics as well as to identify evidence of its use in this field. Fifty-seven studies were finally included, in which four main instruments for identifying flow state, twenty different flow state scales, six categories for designing computer-based learning activities for leading to flow state, sixteen empirical benefits from twenty-five empirical studies and two main flow models were identified.

Three benefits out of sixteen deserve special attention since they were more present in the empirical studies: (1) increase in students' learning; (2) more in-depth reflective process; and (3) students' satisfaction. The results also suggest that Flow Theory can potentially be useful to deal with several concerns that could be addressed in C\&E topics such as students' feeling of achievement, creativity and imagination enforcement, exploratory behavior, facility to accept changes and adaptations, feeling happy, satisfied and cheerful, flash of intensity, influences to empathy and interest in games, internal locus of control, perceived usefulness and ease of use and sense of cognitive presence.

Among the four main instruments used to identify if students achieve the flow state, manual questionnaires were used by the majority of studies. Moreover, less than half of the studies relied on some flow state scale for flow identification, but for the studies that use it, there is a great diversity of FSS been used, highlighting the work by Jackson and Marsh (1996). Our results also show that the majority of papers are not designing computer-based learning activities to drive students to the flow state as well as, for the papers that are designing such activities. They are mostly based on educational games and game-based techniques. Furthermore, few studies are considering flow models as theoretical background for designing computer-based learning activities, however, for the papers that are considering them, almost all used Csikszentmihalyi' theory.

The results presented in this SLR can be useful to the computers and education community since it gathers evidence from the primary studies included in the review, forming a body of knowledge regarding the use of flow theory in C\&E. In this way, we point out important challenges on the topic that could be addressed by further studies, as following: (i) proposing automatic instruments to identify students' flow state; (ii) evaluating existing FSSs as well as proposing FSSs in the context of computers and education; (iii) implementing systematic methods to aid the design of computer-based learning activities for achieving flow state; (iv) considering the reported positive benefits to design further educational systems; $(v)$ conducting more empirical studies (e.g., metaanalysis) to verify the strength of evidence reported in this SLR; and (vi) using and evaluating computer-based learning activities grounded on well-known flow models from the psychology theory.

\section{References}

Achimugu, P., Selamat, A., Ibrahim, R., \& Mahrin, M. N. R. (2014). A systematic literature review of software requirements prioritization research. Information and software technology, 56(6), 568-585. doi: 10.1016/j.infsof.2014.02.001 [GS Search]. 
Admiraal, W., Huizenga, J., Akkerman, S., \& Ten Dam, G. (2011). The concept of flow in collaborative game-based learning. Computers in Human Behavior, 27(3), 1185-1194. doi: 10.1016/j.chb.2010.12.013 [GS Search].

Anderson, T. (Ed.). (2008). The theory and practice of online learning. Athabasca University Press. [GS Search].

Bittencourt, I. I., Baranauskas, M. C., Pereira, R., Dermeval, D., Isotani, S., \& Jaques, P. (2016). A systematic review on multi-device inclusive environments. Universal Access in the Information Society, 15(4), 737-772. doi: 10.1007/s10209-015-0422-3 [GS Search].

Bittencourt, I. I., Costa, E., Silva, M., \& Soares, E. (2009). A computational model for developing semantic web-based educational systems. Knowledge-Based Systems, 22(4), 302-315. doi: 10.1016/j.knosys.2009.02.012 [GS Search].

Boisvert, L. (2000). Web-based learning. Information Systems Management, 17(1), 35-41. doi: $\underline{10.1201 / 1078 / 43190.17 .1 .20000101 / 31212.5}$ [GS Search].

Bozkurt, A., Akgun-Ozbek, E., Yilmazel, S., Erdogdu, E., Ucar, H., Guler, E., ... \& Aydin, C. H. (2015). Trends in distance education research: A content analysis of journals 2009-2013. The International Review of Research in Open and Distributed Learning, 16(1). doi: 10.19173/irrodl.v16i1.1953 [GS Search].

Brusilovsky, P., \& Maybury, M. T. (2002). From adaptive hypermedia to the adaptive web. Communications of the ACM, 45(5), 30-33. doi: 10.1145/506218.506239 [GS Search].

Challco, G. C., Moreira, D., Mizoguchi, R., \& Isotani, S. (2014, June). Towards an ontology for gamifying collaborative learning scenarios. In International Conference on Intelligent Tutoring Systems (pp. 404-409). Springer, Cham. doi: 10.1007/978-3-319-07221-0_50 [GS Search].

Chang, K. E., Wu, L. J., Weng, S. E., \& Sung, Y. T. (2012). Embedding game-based problemsolving phase into problem-posing system for mathematics learning. Computers \& Education, 58(2), 775-786. doi: 10.1016/j.compedu.2011.10.002 [GS Search].

Chen, H., Wigand, R.T., \& Nilan, M. (1999). Optimal experience of Web activities. Computers in Human Behavior, 15(5), 585-608. doi: 10.1016/S0747-5632(99)00038-2 [GS Search].

Connolly, T. M., Boyle, E. A., MacArthur, E., Hainey, T., \& Boyle, J. M. (2012). A systematic literature review of empirical evidence on computer games and serious games. Computers \& Education, 59(2), 661-686. doi: 10.1016/j.compedu.2012.03.004 [GS Search].

Csikszentmihalyi, M. (1990). Flow. The Psychology of Optimal Experience. New York (HarperPerennial) 1990. [GS Search].

Csikszentmihalyi, M. (2000). Beyond boredom and anxiety. Jossey-Bass. [GS Search]. 
D’Mello, S., \& Graesser, A. (2012). Dynamics of affective states during complex learning. Learning and Instruction, 22(2), 145-157. doi: 10.1016/j.learninstruc.2011.10.001 [GS Search].

Dermeval, D., Vilela, J., Bittencourt, I. I., Castro, J., Isotani, S., \& Brito, P. (2014, September). A systematic review on the use of ontologies in requirements engineering. In Software Engineering (SBES), 2014 Brazilian Symposium on (pp. 1-10). IEEE. doi: 10.1109/SBES.2014.13 [GS Search].

Dieste, O., Grimán, A., \& Juristo, N. (2009). Developing search strategies for detecting relevant experiments. Empirical Software Engineering, 14(5), 513-539. doi: 10.1007/s10664-008-9091-7 [GS Search].

Ding, W., Liang, P., Tang, A., \& Van Vliet, H. (2014). Knowledge-based approaches in software documentation: A systematic literature review. Information and Software Technology, 56(6), 545-567. doi: 10.1016/j.infsof.2014.01.008 [GS Search].

dos Santos, W. O., \& da Silva Junior, C. G. State of the Art in Educational Games Virtualization. RENOTE, 14(1). doi: 10.22456/1679-1916.67347 [GS Search].

dos Santos, W. O., Gomes, T., \& Silva, C. (2017, October). Towards to Flow State Identification in Educational Games: An Empirical Study. In Brazilian Symposium on Computers in Education (Vol. 28, No. 1, p. 927). doi: 10.5753/cbie.sbie.2017.927 [GS Search].

Dybå, T., \& Dingsøyr, T. (2008). Empirical studies of agile software development: A systematic review. Information and software technology, 50(9), 833-859. doi: 10.1016/j.infsof.2008.01.006 [GS Search].

Eisenberger, R., Jones, J. R., Stinglhamber, F., Shanock, L., \& Randall, A. T. (2005). Flow experiences at work: For high need achievers alone?. Journal of Organizational Behavior, 26(7), 755 775. doi: 10.1002/job.337 [GS Search].

Faiola, A., Newlon, C., Pfaff, M., \& Smyslova, O. (2013). Correlating the effects of flow and telepresence in virtual worlds: Enhancing our understanding of user behavior in game-based learning. Computers in Human Behavior, 29(3), 1113-1121. doi: 10.1016/j.chb.2012.10.003 [GS Search].

Fu, F. L., Su, R. C., \& Yu, S. C. (2009). EGameFlow: A scale to measure learners' enjoyment of elearning games. Computers \& Education, 52(1), 101-112. doi: 10.1016/j.compedu.2008.07.004 [GS Search].

Hamari, J., Shernoff, D. J., Rowe, E., Coller, B., Asbell-Clarke, J., \& Edwards, T. (2016). Challenging games help students learn: An empirical study on engagement, flow and immersion in game-based learning. Computers in Human Behavior, 54, 170-179. doi: $\underline{\text { 10.1016/j.chb.2015.07.045 [GS Search]. }}$ 
Hernandes, E., Zamboni, A., Fabbri, S., \& Thommazo, A. D. (2012). Using GQM and TAM to evaluate StArt-a tool that supports Systematic Review. CLEI Electronic Journal, 15(1), 3-3. [GS Search].

Heutte, J., Fenouillet, F., Boniwell, I., Martin-Krumm, C., \& Csikszentmihalyi, M. (2013). EduFlow: Proposal for a new measure of flow in education. Manuscript sumbitted for publication/Manuscrit soumis pour publication, 38-p. [GS Search].

Hoffman, D. L., \& Novak, T. P. (1996) "Marketing in hypermedia computer-mediated environments: Conceptual foundations". Journal of Marketing, 60(2), 50-68. doi: 10.2307/1251841 [GS Search].

Ibáñez, M. B., Di Serio, Á., Villarán, D., \& Kloos, C. D. (2014). Experimenting with electromagnetism using augmented reality: Impact on flow student experience and educational effectiveness. Computers \& Education, 71, 1-13. doi: 10.1016/j.compedu.2013.09.004 [GS Search].

Jackson, S. A., \& Eklund, R. C. (2002). Assessing flow in physical activity: The flow state scale-2 and dispositional flow scale-2. Journal of Sport and Exercise Psychology, 24(2), 133-150. doi:

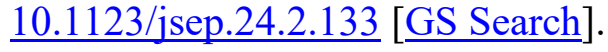

Jackson, S. A., \& Marsh, H. W. (1996). Development and validation of a scale to measure optimal experience: The Flow State Scale. Journal of sport and exercise psychology, 18(1), 17-35. doi: 10.1123/jsep.18.1.17 [GS Search].

Jonassen, D., \& Land, S. (Eds.). (2012). Theoretical foundations of learning environments. Routledge. [GS Search].

Katuk, N., Omar, M., \& Halim, N. (2014, December). Improving Engagement in Hypermedia Learning: A Design for Navigation Support. In Proceedings of the 16th International Conference on Information Integration and Web-based Applications \& Services (pp. 40-43). ACM. doi: $10.1145 / 2684200.2684316$ [GS Search].

Kiili, K. (2006). Evaluations of an experiential gaming model. Human Technology: An Interdisciplinary Journal on Humans in ICT Environments, 2(2), 187-201. Available at: https://jyx.jyu.fi/handle/123456789/20195 [GS Search].

Kiili, K., \& Lainema, T. (2008). Foundation for measuring engagement in educational games. Journal of Interactive Learning Research, 19(3), 469. Available at: https://www.learntechlib.org/primary/p/24197/ [GS Search].

Kiili, K., de Freitas, S., Arnab, S., \& Lainema, T. (2012). The design principles for flow experience in educational games. Procedia Computer Science, 15, 78-91. doi: 10.1016/j.procs.2012.10.060 [GS Search].

Kim, N. Y. (2009). The structural relationship among academic motivation, program, organizational support, interaction, flow and learning outcome in cyber education. Unpublished doctoral dissertation). Ewha Womans University, Seoul, Korea. 
Kitchenham B, Charters S (2007) Guidelines for performing systematic literature reviews in software engineering. In: Technical report EBSE 2007-001, Keele University and Durham University Joint Report

Kitchenham, B. (2004). Procedures for performing systematic reviews. Keele, UK, Keele University, 33(2004), 1-26. [GS Search].

Kitchenham, B. (2007). Empirical paradigm-the role of experiments. Empirical Software Engineering Issues. Critical Assessment and Future Directions, 25-32. doi: 10.1007/978-3-540-71301$\underline{2} 9$ [GS Search].

Mahdavi-Hezavehi, S., Galster, M., \& Avgeriou, P. (2013). Variability in quality attributes of service-based software systems: A systematic literature review. Information and Software Technology, 55(2), 320-343. doi: 10.1016/j.infsof.2012.08.010 [GS Search].

Martin, A. J., \& Jackson, S. A. (2008). Brief approaches to assessing task absorption and enhanced subjective experience: Examining 'short'and 'core'flow in diverse performance domains. Motivation and Emotion, 32(3), 141-157. doi: 10.1007/s11031-008-9094-0 [GS Search].

Massimini, F. (1988). The systematic assessment of flow in daily experience, Optimal Experience. Psychological Studies of Flow in Consciousness, 266-287. [GS Search].

Novak, T. P., Hoffman, D. L., \& Yung, Y. F. (2000). Measuring the customer experience in online environments: A structural modeling approach. Marketing science, 19(1), 22-42. doi: $\underline{10.1287 / \mathrm{mksc} \text {.19.1.22.15184 [GS Search]. }}$.

Paiva, R. O. A., Bittencourt, I. I., da Silva, A. P., Isotani, S., \& Jaques, P. (2015, April). Improving pedagogical recommendations by classifying students according to their interactional behavior in a gamified learning environment. In Proceedings of the 30th Annual ACM Symposium on Applied Computing (pp. 233-238). ACM. doi: 10.1145/2695664.2695874 [GS Search].

Pavlas, D., Heyne, K., Bedwell, W., Lazzara, E., \& Salas, E. (2010, September). Game-based learning: The impact of flow state and videogame self-efficacy. In Proceedings of the human factors and ergonomics society annual meeting (Vol. 54, No. 28, pp. 2398-2402). Sage CA: Los Angeles, CA: SAGE Publications. doi: 10.1177/154193121005402808 [GS Search].

Payne, B. R., Jackson, J. J., Noh, S. R., \& Stine-Morrow, E. A. (2011). In the zone: flow state and cognition in older adults. Psychology and aging, 26(3), 738. doi: $\underline{10.1037 / a 0022359}$ [GS Search].

Rheinberg, F., Vollmeyer, R., \& Engeser, S. (2003). Die Erfassung des Flow-Erlebens [Measuring flow experiences]. In J. Stiensmeier-Pelster \& F. Rheinberg (Eds.), Diagnostik von Motivation und Selbstkonzept. Tests und Trends (Vol. 2, pp. 261-279). [GS Search].

Roberts, A. L. (2009). Children's reflections on cultural differences in ways of working together. University of California, Santa Cruz. [GS Search]. 
Rodriguez-Sanchez, A. M., Schaufeli, W. B., Salanova, M., \& Cifre, E. (2008). Flow experience among information and communication technology users. Psychological Reports, 102(1), 29-39. doi: 10.2466/pr0.102.1.29-39 [GS Search].

Sala, T. (2013) "Game Design Theory Applied: The Flow Channel”. Available at http://tinyurl.com/SalaFlowApplied. Accessed May, 19th, 2015.

Santos, W. O., Bittencourt, I. I., Isotani, S., Silveira, F. I., \& Marques, L. B. (2015). Challenges of Flow Theory Applied to Computers in Education. In IV Workshop of Challenges of Computer in Education. Recife-PE, Brazil. [GS Search].

Santos, W. O.; Silva Junior, C. G. (2014) "Uso de Jogos no ensino da Matemática: Uma análise entre os jogos tradicionais e os jogos digitais, baseada em pesquisa e mapeamento dos materiais encontrados na Web”. In: X Seminário Jogos Eletrônicos, Educação e Comunicação. Salvador BA. (in Portuguese) [GS Search].

Schell, J. (2014). The Art of Game Design: A book of lenses. CRC Press. [GS Search].

Scoresby, J., \& Shelton, B. E. (2011) "Visual perspectives within educational computer games: effects on presence and flow within virtual immersive learning environments". Instructional Science, 39(3), 227-254. doi: 10.1007/s11251-010-9126-5 [GS Search].

Seifert, T., Radu, O., \& Doyle, A. (2010). Flow: An emotional experience in mathematics problem solving. In Interdisciplinary for the Twenty-First Century: Proceedings of the Third International Symposium on Mathematics and Its Connections to Arts and Sciences (pp. 139-154).

Shernoff, D. J., \& Csikszentmihalyi, M. (2009). Cultivating engaged learners and optimal learning environments. Handbook of positive psychology in schools, 131-145. [GS Search].

Shin, N. (2006). Online learner's 'flow'experience: an empirical study. British Journal of Educational Technology, 37(5), 705-720. doi: 10.1111/j.1467-8535.2006.00641.x [GS Search].

Sinnamon, S., Moran, A., \& O’Connell, M. (2012). Flow among musicians: measuring peak experiences of student performers. Journal of Research in Music Education, 60(1), 6-25. doi: $\underline{10.1177 / 0022429411434931}$ [GS Search].

Steenbergen-Hu, S., \& Cooper, H. (2014). A meta-analysis of the effectiveness of intelligent tutoring systems on college students' academic learning. Journal of Educational Psychology, 106(2), 331. [GS Search].

Wohlin C, Runeson P, Ho“st M, Ohlsson MC, Regnell B, Wessle'n A (2000) Experimentation in software engineering: an introduction. Kluwer Academic Publishers, Norwell. [GS Search].

Woolf, B. P. (2010). Building intelligent interactive tutors: Student-centered strategies for revolutionizing e-learning. Morgan Kaufmann. [GS Search]. 
Wu, W., \& Chen, L. (2015, June). Implicit acquisition of user personality for augmenting movie recommendations. In International Conference on User Modeling, Adaptation, and Personalization (pp. 302-314). Springer, Cham. doi: 10.1007/978-3-319-20267-9_25 [GS Search].

Yoshida, K., Asakawa, K., Yamauchi, T., Sakuraba, S., Sawamura, D., Murakami, Y., \& Sakai, S. (2013). The flow state scale for occupational tasks: development, reliability, and validity. Hong Kong Journal of Occupational Therapy, 23(2), 54-61. doi: 10.1016/j.hkjot.2013.09.002 [GS Search].

\section{Appendix}

\section{A. General Appendix}

- The full list of appendices related to this article, as well, the other related materials, such as the figures, the original data used in this study and the possible erratum of study can be accessed from this link (or contacting the authors by email): https://goo.gl/qNDuYL 